\title{
The Distinctive Clinical Features of Paraneoplastic Sensory Neuronopathy
}

\author{
Colin H. Chalk, Anthony J. Windebank, David W. Kimmel and Philip G. McManis
}

\begin{abstract}
A 15-year experience with paraneoplastic sensory neuronopathy at the Mayo Clinic is reviewed. Of 26 patients with paraneoplastic sensory neuronopathy, 19 had small cell lung cancer, 4 had breast cancer, and 3 had other neoplasms. There was a striking predominance of females (20:6). Neuropathic symptoms (pain, paresthesia, sensory loss) were asymmetric at onset, with a predilection for the upper limbs; in three patients, symptoms were confined to the arms. Electrophysiologic testing revealed absent sensory responses and normal or minimally altered motor responses. Slightly more than half the patients had associated autonomic, cerebellar, or cerebral abnormalities. In some patients, treatment of the neoplasm seemed to halt progression of the neuronopathy, but none had neurologic improvement and most continued to worsen, even when the oncologic response was good. Distinguishing between paraneoplastic and nonparaneoplastic sensory neuronopathies can be difficult, but prominent neuropathic pain, neurologic dysfunction involving more than the peripheral sensory system, or an increased cerebrospinal fluid protein value should prompt a careful search for a cancer.
\end{abstract}

RÉSUMÉ: Manifestations cliniques caractéristiques de la neuronopathie sensitive paranéoplasique. Nous revoyons quinze années d'expérience avec la neuronopathie sensitive paranéoplasique à la clinique Mayo. Des 26 patients avec neuronopathie sensitive paranéoplasique, 19 avaient un cancer du poumon à petites cellules, 4 avaient un cancer du sein et 3 avaient d'autres néoplasies. La prédominance des femmes était frappante (20:6). Les symptômes neuropathiques (douleur, paresthésie, perte sensitive) étaient asymétriques au début, avec une prédilection pour les membres supérieurs; chez trois patients, les symptômes étaient limités aux bras. Les épreuves électrophysiologiques ont montré une absence de réponse sensitive et des réponses motrices normales ou peu altérées. Un peu plus de la moitié des patients avaient des anomalies autonomiques, cérébelleuses ou cérébrales associées. Chez certains patients, le traitement de la néoplasie a semblé arrêter la progression de la neuronopathie, mais aucun n'a eu d'amélioration sue le plan neurologique et la plupart ont continué de se détériorer, même quand la réponse oncologique était bonne. Il peut être difficile de faire la distinction entre les neuronopathies sensitives paranéoplasiques et non-paranéoplasiques. Cependant, une douleur neuropathique importante, une dysfonction neurologique impliquant plus d'un système sensitif périphérique ou une augmentation de la protéinémie du liquide céphalo-rachidien devrait inciter à la recherche minutieuse d'un cancer.

Can.J. Neurol.Sci. 1992; 19: 346-35I

In 1948, Denny-Brown' described two middle-aged patients with a profound sensory neuropathy that developed over several months. No cause was apparent during life, but autopsy showed that both patients had oat cell bronchogenic carcinoma. Neuropathologic findings were severe degeneration of the dorsal columns of the spinal cord and degeneration of the dorsal root ganglia with marked loss of the ganglion cells. Denny-Brown postulated that the neurologic syndrome was the consequence of a metabolic disturbance produced by the tumor cells.

Throughout the 1950s and 1960s, several similar patients were described, and the concept of a sensory neuropathy arising as a remote effect of cancer became widely recognized. ${ }^{2-6}$ Twentynine patients with a profound sensory neuropathy associated with cancer had been reported by $1977,{ }^{7}$ and several more case reports have been published since then.$^{8-11}$
The term "subacute sensory neuronopathy" has been applied to this syndrome by some workers;" "neuronopathy" emphasizes that the sensory neuron cell body is the presumed primary site of injury. We prefer the term "paraneoplastic sensory neuronopathy" (PSN) because the evolution of symptoms and signs is often more protracted than subacute.

Although PSN is well known, it is rare. Our understanding of the clinical features of PSN is based on a small number of patients, and there are several unsettled questions about the syndrome. Is PSN strongly associated with certain neoplasms? In the early literature, small cell bronchogenic carcinoma was associated with PSN, but various other tumors have been reported. Some cases of PSN appear to be part of a more widespread paraneoplastic encephalomyelitis, but whether such cases are the exception or the rule is uncertain. Neurologic outcome in PSN

From the Department of Neurology, Mayo Clinic and Mayo Foundation, Rochester, Minnesota

Received August 19, 1991. Accepted in final form March 4, 1992

Reprint requests to: Dr. A. J. Windebank, Mayo Clinic, 1501 Guggenheim Building, 200 First Street SW, Rochester, Minnesota 55905, U.S.A. 
has been reported to be uniformly poor; the effect of improved, modern antineoplastic treatments on neurologic prognosis is unclear. Are there clinical or laboratory features that allow one to distinguish PSN from cases of non-cancer-associated sensory neuronopathy? In this article, we describe the clinical, laboratory, and electrophysiologic features of a series of patients with PSN to shed some light on these and other questions.

\section{METHODS}

The case histories of all patients with a diagnosis of peripheral neuropathy in association with malignant disease who were seen at the Mayo Clinic between 1975 and 1989 were reviewed. The following criteria were used to define patients with PSN: 1) Presence of a progressive neuropathy, which on clinical grounds appeared to be purely or predominantly sensory, particularly with impaired proprioception and areflexia. Patients with indolent distal neuropathies with normal reflexes ("burning-feet" type) were excluded. 2) Cancer diagnosed within 6 years of the onset of neuropathy. Patients with only squamous cell or basal cell carcinoma of the skin were excluded. 3) No other cause of a sensory neuronopathy present, such as cisplatin toxicity, pyridoxine abuse, or Sjögren's syndrome.

The 26 patients who met these criteria are the subject of this report. All had been examined by a Mayo Clinic neurologist. Most of the patients had had electrophysiologic and cerebrospinal fluid examinations, but these were not required for inclusion.
Nerve conduction studies were performed in 23 patients with standard techniques using surface electrodes for stimulation and recording, and careful attention was given to limb temperature. ${ }^{12}$ Sensory nerve conduction studies were antidromic, stimulating at the wrist and recording over the index finger for the median nerve and over the little finger for the ulnar nerve, and stimulating over the calf and recording behind the lateral malleolus for the sural nerve. Findings were compared with reference values established in the Mayo Clinic Electromyography Laboratory from the study of normal volunteers over the past 30 years (unpublished data). Concentric needle electromyography was performed in all 23 patients, and at least three muscles were examined in each patient (mean, 8.3; range, 3 to 17). Spontaneous electrical activity and voluntarily activated motor unit potentials were sampled in three or more areas in each muscle.

\section{RESULTS}

Clinical features of the 26 patients are summarized in Table 1. All were of middle age or older at the onset of the neuronopathy (mean age, 59.6 years; range, 45 to 73 years). Women were affected three times more often than men (20:6). The associated neoplasms were small cell lung cancer (19 patients, all were smokers), breast adenocarcinoma (4 patients), ovarian cancer, lymphoma, and mucinous adenocarcinoma in which the primary site was unknown ( 1 patient each). The onset of the neuronopathy preceded the diagnosis of tumor in all but three cases,

Table 1. Clinical Data from 26 Patients with Paraneoplastic Sensory Neuronopathy

\begin{tabular}{|c|c|c|c|c|c|c|}
\hline Case & Sex & $\begin{array}{c}\text { Age at Onset of } \\
\text { Neuronopathy, } \\
\text { yr }\end{array}$ & $\begin{array}{l}\text { Presenting } \\
\text { Symptoms }^{\mathrm{a}}\end{array}$ & $\begin{array}{l}\text { Site of Presenting } \\
\text { Symptoms }\end{array}$ & Neoplasm & $\begin{array}{c}\text { Interval, } \\
\text { mo }^{\mathbf{b}}\end{array}$ \\
\hline 1 & $\mathrm{~F}$ & 58 & $\mathrm{Pn}, \mathrm{Ps}$ & Right arm & $\mathrm{SCC}^{\mathrm{c}}$ & +3 \\
\hline 3 & $\mathrm{~F}$ & 64 & Pn, Ps, S & Feet & SCC & +11 \\
\hline 4 & $\mathrm{~F}$ & 62 & Ps & Right hand & SCC & +5 \\
\hline 5 & $\mathrm{~F}$ & 67 & $\mathrm{Pn}, \mathrm{S}$ & Right hand & SCC & +20 \\
\hline 8 & $\mathrm{~F}$ & 49 & Ps, S & Distal limbs & SCC & +0.5 \\
\hline 9 & $\mathrm{~F}$ & 68 & Pn, S, Ps & Limbs & SCC & +11 \\
\hline 10 & $\mathrm{~F}$ & 62 & $\mathrm{Pn}$ & Right arm & $\mathrm{SCC}$ & +5 \\
\hline 11 & $\mathrm{~F}$ & 58 & Ps & Distal limbs & SCC & +4 \\
\hline 12 & M & 65 & $S$ & Toes & SCC & +10 \\
\hline 13 & $\mathrm{M}$ & 63 & Ps & Arms & $\mathrm{SCC}$ & +62 \\
\hline 14 & $\mathbf{M}$ & 61 & Ps & Right hand & SCC & +3 \\
\hline 20 & $\mathrm{~F}$ & 45 & $\mathrm{Pn}, \mathrm{S}$ & Left hand & Breast & -14 \\
\hline 21 & $\mathrm{~F}$ & 73 & $\mathrm{Pn}, \mathrm{Ps}$ & Hands & Breast & +5 \\
\hline 22 & $\mathrm{~F}$ & 47 & $\mathrm{~S}$ & Left leg & Breast & +11 \\
\hline 23 & $\mathrm{~F}$ & 64 & $\mathrm{~S}$ & Right hand & Breast & +10 \\
\hline 24 & $\mathrm{~F}$ & 56 & Ps, S & Hands & $\begin{array}{l}\text { Adenocarcinoma, } \\
\text { primary unknown }\end{array}$ & +3 \\
\hline 25 & $\mathbf{M}$ & 52 & $\mathrm{~S}$ & Hands, feet & Lymphoma & -1 \\
\hline 26 & $\mathrm{~F}$ & 56 & Ps, $S$ & Hands, feet & Ovary & -3 \\
\hline
\end{tabular}

"Pn, pain; Ps, paresthesia; S, sensory loss; $W$, weakness.

${ }^{\mathrm{b}}$ The interval is the time from onset of neuronopathy to diagnosis of neoplasm. Negative numbers indicate cases in which neuronopathy began after the diagnosis of neoplasm.

'SCC, small cell lung cancer. 
and the median interval from onset of the neuronopathy to diagnosis of the neoplasm was 5 months. The longest interval between onset of the neuronopathy and diagnosis of cancer was 62 months. (However, this patient sought medical advice reluctantly and infrequently, and his small cell lung cancer was far advanced at diagnosis.) Disabling neurologic symptoms developed over a few days in 2 patients, but symptoms and signs evolved more gradually, over 2 to 9 months, in the other 24 .

\section{Symptoms}

The presenting neuropathic symptoms were pain (13 patients), paresthesia (13 patients), and sensory loss (13 patients), occurring either alone or, more often, in combination. The distribution of the presenting symptoms was distinctive in many patients. Fifteen of the 26 patients first had symptoms in the upper limbs alone. Symptoms remained restricted to the upper limbs for intervals ranging from 1 week to 19 months (median, 3 months) before involving the legs; three patients never reported symptoms in the legs, although they were areflexic at the knees and ankles and had low-amplitude or absent sural sensory action potentials. The symptoms in the upper limbs early in the course of their illness prompted carpal tunnel surgery in four patients and an ulnar nerve transposition in one. Marked asymmetry of symptoms at onset was also common, occurring in 11 patients. For example, one patient had worsening pain and increasing sensory loss confined to the right upper limb for 9 months before the left side was involved.

\section{Signs}

Proprioceptive loss, which was found in all patients, was severe and frequently involved the wrist and ankle joints. Pseudoathetosis was observed in 10 patients. Global hyporeflexia or areflexia was the general rule, except in one patient, in whom areflexia was limited to the arms (as were symptoms) at the time of examination. There was moderate to severe nociceptive loss in 18 patients. Several patients initially judged to have moderate or severe weakness proved to have normal or minimally abnor- mal motor studies on electrophysiologic testing. From repeated clinical examinations that attempted to compensate for impaired proprioception by using visual cues, it was concluded that strength in these patients was in fact normal or at most minimally decreased.

\section{Associated Neurologic Syndromes}

In 15 of the 26 patients, the sensory neuronopathy was the predominant feature of a more widespread neurologic illness. The associated neurologic syndromes are summarized in Table 2. Five patients had signs of autonomic dysfunction (combinations of orthostatic hypotension, sudomotor failure, and nonreactive pupils), and four others had suggestive symptoms (impotence, dry mouth, and constipation). Four patients had cerebellar dysarthria or oculomotor signs; because cerebellar and sensory ataxia may be difficult to distinguish from one another, ataxia alone was not considered to constitute cerebellar dysfunction. Two patients had encephalopathic features, including personality change, partial seizures, and chorea. The syndrome of inappropriate antidiuretic hormone secretion was found in one patient. Several other neurologic abnormalities occurred in six patients (transient diplopia, ageusia, Adie's pupil, subdural hematoma, occasional myoclonus). The relationship of these abnormalities to the patients' cancer is uncertain.

\section{Laboratory Tests}

Results of routine laboratory tests were generally unremarkable. Sedimentation rates were modestly increased in a few patients, but more often they were normal. Most patients had testing for antinuclear antibodies, but a systematic search for serum autoantibodies was not performed. Only one patient had a significant antinuclear antibody titer (1:640, speckled). Antineuronal nuclear antibodies ${ }^{13}$ were found in all five patients with small cell lung cancer who were tested.

Of the 26 patients, 18 had cerebrospinal fluid obtained: 13 had an increased protein value (mean, $104 \mathrm{mg} / \mathrm{dL}[1.04 \mathrm{~g} / \mathrm{L}]$; range, 48 to 230 [0.48 to $2.3 \mathrm{~g} / \mathrm{L}]), 1$ had an increased protein

Table 2. Neurologic Syndromes Associated with Paraneoplastic Sensory Neuronopathy

\begin{tabular}{|c|c|c|c|c|c|}
\hline \multirow[b]{2}{*}{ Case } & \multicolumn{2}{|c|}{ Autonomic Dysfunction } & \multirow[b]{2}{*}{ Cerebellar Disorder } & \multirow[b]{2}{*}{ Encephalopathy } & \multirow[b]{2}{*}{ Other } \\
\hline & Definite & Possible & & & \\
\hline 2 & $\mathrm{OH},{ }^{\mathrm{a}}$ anhidrosis & $\cdots$ & Dysarthria & $\cdots$ & $\cdots$ \\
\hline 5 & $\ldots$ & $\cdots$ & $\ldots$ & $\cdots$ & Ageusia \\
\hline 6 & $\mathrm{OH}$ & $\cdots$ & $\cdots$ & $\cdots$ & $\ldots$ \\
\hline 7 & $\mathrm{OH}$, anhidrosis, gastroparesis & $\cdots$ & $\cdots$ & $\cdots$ & $\ldots$ \\
\hline 8 & $\mathrm{OH}$, pupillary paralysis & $\cdots$ & $\cdots$ & $\cdots$ & SIADH $^{\mathrm{b}}$ \\
\hline 9 & $\cdots$ & $\cdots$ & $\cdots$ & $\begin{array}{l}\text { Chorea, partial } \\
\text { seizures, dysphasia }\end{array}$ & $\cdots$ \\
\hline 10 & $\cdots$ & $\begin{array}{l}\text { Dry mouth, } \\
\text { constipation }\end{array}$ & $\cdots$ & - . & $\cdots$ \\
\hline 11 & $\mathrm{OH}$ & $\ldots$ & Nystagmus & $\cdots$ & $\cdots$ \\
\hline 12 & $\cdots$ & Impotence & $\ldots$ & $\cdots$ & $\cdots$ \\
\hline 13 & $\cdots$ & Impotence & $\cdots$ & $\cdots$ & $\cdots$ \\
\hline 14 & $\cdots$ & $\cdots$ & $\cdots$ & $\begin{array}{l}\text { Personality change, } \\
\text { dementia }\end{array}$ & Adie's pupil \\
\hline 16 & $\cdots$ & Impotence & Nystagmus & $\cdots$ & Transient diplopia \\
\hline 17 & $\cdots$ & $\cdots$ & Dysarthria & $\cdots$ & Transient diplopia \\
\hline 21 & $\cdots$ & $\cdots$ & $\ldots$ & $\cdots$ & Occasional myoclonus \\
\hline 26 & $\cdots$ & $\cdots$ & $\cdots$ & $\cdots$ & Subdural hematoma \\
\hline
\end{tabular}

aOH, orthostatic hypotension.

'SIADH, syndrome of inappropriate antidiuretic hormone secretion. 
value and mild pleocytosis (protein, $90 \mathrm{mg} / \mathrm{dL}[0.9 \mathrm{~g} / \mathrm{L}] ; 8.0$ lymphocytes $/ \mu \mathrm{L}$ ), and 4 had normal results. Cytologic examinations for malignant cells were all negative. The cerebrospinal fluid results did not correlate with whether or not neurologic dysfunction involved more than the peripheral sensory system.

\section{Sural Nerve Biopsies}

Sural nerve biopsies in four patients showed severe but nonspecific decreased myelinated fiber density and axonal degeneration. The biopsy specimen of one patient also had collections of mononuclear inflammatory cells surrounding epineurial ves-

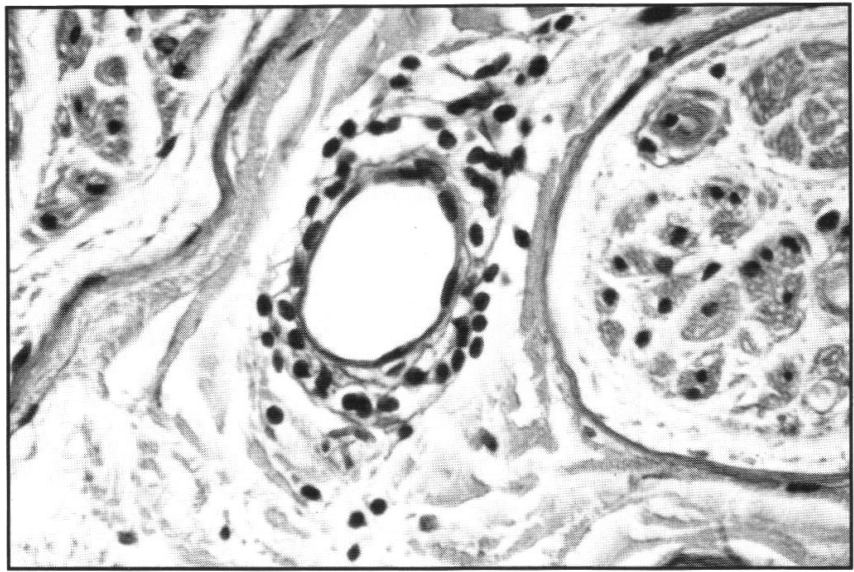

Figure I (case II) - Sural nerve specimen, showing a cuff of mononuclear inflammatory cells around an epineurial vessel; angionecrosis is not present. (Hematorylin-eosin; $.1, I 20$. ) sels, but neither infiltration nor necrosis of vessel walls was seen (Figure 1).

\section{Electrophysiologic Tests (Figure 2)}

Sensory nerve action potentials were universally absent in all but four patients, who had one or more preserved sensory responses. Among the 65 sensory nerve conduction studies, there were only two responses within the normal amplitude range. No sensory conduction velocities could be measured because responses could not be obtained with proximal sites of stimulation.

In contrast, mean compound muscle action potential amplitudes and mean motor conduction velocities did not differ significantly from established normal values. However, all but three patients had one or more motor nerves with an abnormal compound muscle action potential amplitude, conduction velocity, or distal latency.

Eleven patients had no abnormal spontaneous electromyographic activity at rest, and eight others had occasional fibrillation potentials in foot, hand, or paraspinal muscles. In four patients, some distal limb muscles had a moderate density of fibrillation potentials. Motor unit potentials were normal in three patients, and in the remainder they were mildly increased in amplitude or duration in distal limb muscles.

\section{Outcome}

Adequate follow-up information was available in 14 of the 26 patients. The mean duration of follow-up after the diagnosis of cancer was 18 months (range, 1 to 60 months). Among these 14 patients, 12 received antineoplastic treatment ( 7 had small cell lung cancer, 3 breast cancer, 1 lymphoma, and 1 adenocarcinoma

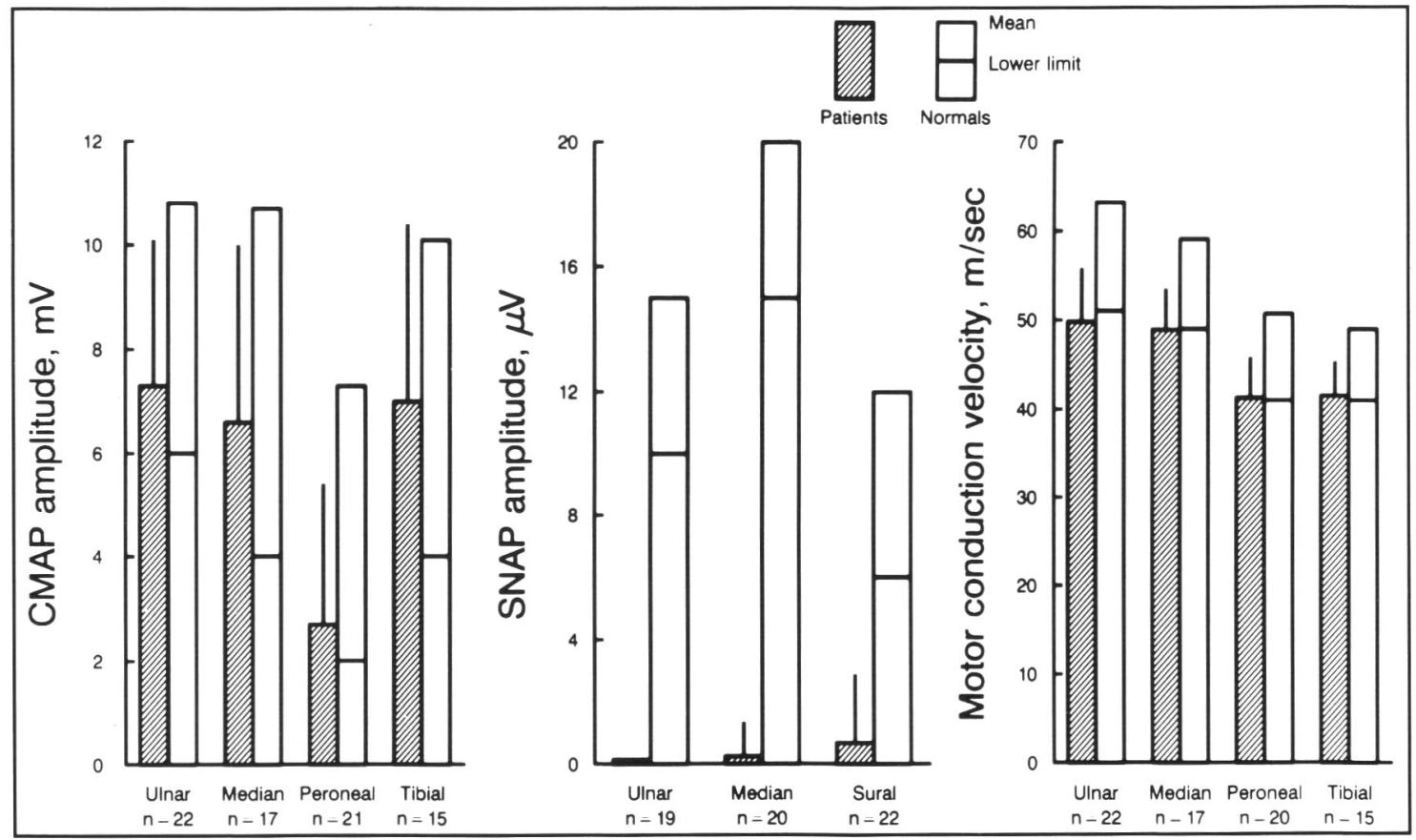

Figure 2 - Mean amplitudes of compound muscle action potentials (CMAP), sensory nerve action potentials (SNAP), and motor conduction velocities of patients (hatched bars) compared with normal values for our laboratory (open bars). The vertical lines on the hatched hars indicate one standard deviation above the mean. Mean motor nerve values of patients, although decreased, were within normal limits, whereas SNAP amplitudes were grossly decreased. 
of unknown primary site); 9 of these 12 had clear oncologic improvement, but none had neurologic improvement. The neuronopathy relentlessly worsened in seven patients, but progression seemed to cease after antineoplastic treatment in five patients.

Seven patients were treated with prednisone and two with plasma exchange, but these therapies were not given in a systematic fashion. Convincing improvement was seen in only one patient, in whom orally administered prednisone improved hand function and walking ability and lessened paresthesia on two occasions over 24 months; this improvement was followed by deterioration as the dose was reduced. When the prednisone dose was increased for a third time, improvement no longer occurred.

\section{Discussion}

The 26 patients with PSN reported here bring the number of well-described cases to approximately 60 . Several clinical points can be made about the syndrome on the basis of our experience at a single large referral center.

Small cell lung cancer appears to have a specific relationship with PSN, in that it occurred in three-fourths of our patients. An association with small cell lung cancer was suggested by the early case reports ${ }^{1.4}$ and the London Hospital experience, ${ }^{5.6}$ but Horwich et al. ${ }^{7}$ found this tumor in only one of their seven cases. Our experience lends strong support to the idea that, among neoplasms, small cell lung cancer has a peculiar predilection for producing PSN, as it does for the LambertEaton myasthenic syndrome. ${ }^{14}$ In contrast, ovarian cancer, which frequently occurs with paraneoplastic cerebellar degeneration, occurred in only one of our patients.

We found a striking predominance of female patients in our series (20:6). If the five cases with breast or ovarian cancer are excluded, females still account for $70 \%$ of the patients. This predominance is particularly notable because small cell lung cancer is much more common in males. For example, in a roughly contemporary Mayo Clinic series of 640 cases of small cell lung cancer, only $16 \%$ of the patients were female. ${ }^{15} \mathrm{~A}$ female predominance is not apparent in the early cases of PSN, although all seven of the patients of Horwich et al. ${ }^{7}$ were women.

The distribution of neuropathic symptoms and signs was distinctive in many of our patients - only the upper limbs were involved at the onset in more than half the patients, and marked asymmmetry occurred in more than a third. This pattern does not seem to have been reported frequently in PSN in the past, although it was mentioned by Asbury and Johnson ${ }^{16}$ and by Henson and Urich. ${ }^{6}$ Profound proprioceptive loss, with pseudoathetosis in some cases, was present in all patients. Most patients also had impaired nociception, producing a clinical picture of mixed sensory loss. About half of our patients had associated neurologic syndromes, consisting of various combinations of autonomic, cerebellar, and cerebral dysfunction, similar to that observed by others. ${ }^{6.7 .17}$

The only biochemical abnormality that occurred commonly in our patients was elevated cerebrospinal fluid protein. The sedimentation rate, often assumed to be a sensitive but nonspecific clue to underlying cancer, was normal in most of our patients. Electrophysiologic testing showed a marked disparity between sensory and motor nerves; sensory action potentials were generally unobtainable, whereas motor nerve conduction velocities were normal or only minimally altered. In some patients, this electrophysiologic picture provided helpful support for the clinical impression that the weakness reported by some patients was due to deafferentation. The mild motor unit potential changes or sparse fibrillation potentials that were commonly observed with needle electromyography illustrate that what appears to be a pure sensory neuropathy clinically is often a predominantly sensory neuropathy electrophysiologically. This observation was also made by Horwich et al. ${ }^{7}$ in three of four patients, and careful reading of the early case reports shows that mild motor signs were often present. Sural nerve biopsies were abnormal but nondiagnostic, and we believe that nerve biopsy is not helpful in the diagnosis of PSN. Perivascular inflammatory cells were seen in the epineurium of one biopsy specimen. This finding suggests the presence of an inflammatory or immunologically mediated process, but it is nonspecific.

Serum antineuronal nuclear antibodies ${ }^{13}$ were found in the five patients with small cell lung cancer in whom they were sought. These autoantibodies, also called anti-Hu, ${ }^{17}$ have been found by other investigators in patients with PSN and small cell lung cancer. The diagnostic role of antineuronal nuclear antibodies is uncertain. Most patients with these autoantibodies are reported to have a paraneoplastic syndrome (usually PSN) associated with small cell lung cancer, although some patients have the cancer but are normal neurologically. ${ }^{18}$ Whether antineuronal nuclear antibodies can reliably distinguish PSN from other types of sensory neuronopathies is unknown. We are currently investigating this question.

The prognosis for patients with PSN in our series was poor; none of the patients improved, and those in whom progression of the neuronopathy ceased were left with significant disability. At best, successful treatment of the underlying neoplasm seemed to be associated with stabilization of the neuronopathy in a few cases, but more often the neuronopathy pursued a relentless, independent course. Likewise, prednisone was without effect except in one patient, who had a transient benefit. Although remission has been described in PSN associated with lymphoma, ${ }^{9}$ a poor outcome and a lack of response to treatment have been the general experience in PSN, ${ }^{6,17}$ despite improvements in modern antineoplastic therapies for small cell lung cancer. This poor outcome is in contrast to paraneoplastic LambertEaton myasthenic syndrome, in which successful antineoplastic treatment produces neurologic improvement in most cases. ${ }^{19}$

The differential diagnosis of a sensory neuronopathy in a middle-aged patient may be difficult. If toxins ${ }^{20.21}$ and inherited conditions $^{22}$ can be excluded, three main entities need to be considered: PSN, the ataxic sensory neuropathy associated with Sjögren's syndrome,,$^{23}$ and the so-called idiopathic or acute sensory neuronopathy syndrome. ${ }^{24-26}$ Patients with Sjögren's syndrome can be identified by sicca symptoms, appropriate serum autoantibodies, and lymphocytic infiltration of minor salivary glands on lip biopsy. The distinction between PSN and the idiopathic sensory neuronopathy syndrome is more difficult. Fortytwo patients with idiopathic sensory neuronopathy were seen in 25 years at our institution, a frequency roughly equal to that of PSN. ${ }^{24}$ Some distinctive clinical features, such as asymmetry or onset in the upper limbs, are common to both. Both syndromes may evolve subacutely (over a few days) ) $^{74,25}$ or chronically 
(over months). ${ }^{26}$ However, neurologic dysfunction extending beyond the peripheral sensory system, increased cerebrospinal fluid protein, and prominent neuropathic pain, all of which were common in our series of PSN, are uncommon in the idiopathic syndrome ${ }^{24}$ and should prompt especial vigilance for an underlying cancer, particularly small cell lung cancer.

\section{REFERENCES}

1. Denny-Brown D. Primary sensory neuropathy with muscular changes associated with carcinoma. J Neurol Neurosurg Psychiatry 1948; 11:73-87

2. Smith WT, Whitfield AGW. Malignant sensory neuropathy. Lancet 1955; 1: 282-285.

3. Heathfield KWG, Williams JRB. Peripheral neuropathy and myopathy associated with bronchogenic carcinoma. Brain 1954; 77: $122-137$

4. Bickerstaff ER, Woolf AL. Case 1. Carcinomatous sensory neuropathy associated with a pin head-sized anaplastic carcinoma and plasma cell "encephalitis." Birmingham Med Rev 1958; 20; 355-360.

5. Croft PB, Urich H, Wilkinson M. Peripheral neuropathy of sensorimotor type associated with malignant disease. Brain 1967;90: $31-66$.

6. Henson RA, Urich H. Cancer and the Nervous System: The Neurological Manifestations of Systemic Malignant Disease. Boston: Blackwell Scientific Publications, 1982; 378-380.

7. Horwich MS, Cho L, Porro RS, et al. Subacute sensory neuropathy: a remote effect of carcinoma. Ann Neurol 1977; 2: 7-19.

8. Berciano J, Gutierrez J, Figols J, et al. Polineuropatía sensorial asociada a adenocarcinoma pancreático. Estudio clinicopatológico de un casa seguido 5 años. Rev Clin Esp 1983; 170: 295-297.

9. Sagar HJ, Read DJ. Subacute sensory neuropathy with remission: an association with lymphoma. J Neurol Neurosurg Psychiatry 1982; 45: 83-85.

10. Ohnishi A, Ogawa M. Preferential loss of large lumbar primary sensory neurons in carcinomatous sensory neuropathy. Ann Neurol 1986; 20: 102-104.

11. Graus F, Elkon KB, Cordon-Cardo C, et al. Sensory neuronopathy and small cell lung cancer: antineuronal antibody that also reacts with the tumor. Am J Med 1986; 80: 45-52.
12. Daube JR. Nerve conduction studies. In: Aminoff MJ, ed. Electrodiagnosis in Clinical Neurology. New York: Churchill Livingstone, 1980; 229-264.

13. Lennon VA. Anti-Purkinje cell cytoplasmic and neuronal nuclear antibodies aid diagnosis of paraneoplastic autoimmune neurological disorders (letter to the editor). J Neurol Neurosurg Psychiatry 1989; 52: 1438-1439.

14. O'Neill JH, Murray NMF, Newsom-Davis J. The Lambert-Eaton myasthenic syndrome: a review of 50 cases. Brain 1988; 111: 577-596.

15. Rosenow EC III, Carr DT. Bronchogenic carcinoma. CA 1979; 29: 233-245.

16. Asbury AK, Johnson PC. Pathology of Peripheral Nerve. Philadelphia: WB Saunders, 1978; 82.

17. Anderson NE, Rosenblum MK, Graus F, et al. Autoantibodies in paraneoplastic syndromes associated with small-cell lung cancer. Neurology 1988; 38: 1391-1398.

18. Dalmau J, Furneaux HM, Gralla RJ, et al. Detection of the anti-Hu antibody in the serum of patients with small cell lung cancer - a quantitative Western blot analysis. Ann Neurol 1990; 27: 544-552.

19. Chalk CH, Murray NMF, Newson-Davis J, et al. Response of the Lambert-Eaton myasthenic syndrome to treatment of associated small-cell lung carcinoma. Neurology 1990; 40: 1552-1556.

20. Schaumburg H, Kaplan J, Windebank A, et al. Sensory neuropathy from pyridoxine abuse: a new megavitamin syndrome. $N$ Engl J Med 1983; 309: 445-448.

21. Mollman JE. Cisplatin neurotoxicity (editorial). N Engl J Med 1990; 322: 126-127.

22. Denny-Brown D. Hereditary sensory radicular neuropathy. J Neurol Neurosurg Psychiatry 1951; 14: 237-252.

23. Griffin JW, Cornblath DR, Alexander E, et al. Ataxic sensory neuropathy and dorsal root ganglionitis associated with Sjögren's syndrome. Ann Neurol 1990; 27: 304-315.

24. Windebank AJ, Blexrud MD, Dyck PJ, et al. The syndrome of acute sensory neuropathy: clinical features and electrophysiologic and pathologic changes. Neurology 1990; 40: 584-591.

25. Sterman AB, Schaumburg HH, Asbury AK. The acute sensory neuronopathy syndrome: a distinct clinical entity. Ann Neurol 1980; 7: 354-358.

26. Dalakas M. Chronic idiopathic ataxic neuropathy. Ann Neurol 1986; 19: 545-554 